\title{
Model Pelatihan Siswa Putus Sekolah Studi Kasus Pada Balai Latihan Kerja Propinsi Bengkulu
}

\author{
Syaiful Anwar AB \\ gahenodi@yahoo.com \\ Fakultas Ekonomi dan Bisnis Universitas Bengkulu
}

\begin{abstract}
The purpose of this research is to test the influence of the quality of service to the satisfaction of the training participants at Balai Latikan Kerja (BLK) in Bengkulu Province. The method used in this research is survey with interview approach to get observation data directly. The results of this study indicate that the role of instructors (HR) and methods greatly affect the success of trainees in the future. The positive impact of good service will increase customer satisfaction and loyalty as well as the desire to re-buy, which will increase the income received from the products sold. In order to compete, survive, and grow, the organization is required to be able to meet the needs and desires of customers by providing the best service and quality. Based on the strengths, weaknesses, opportunities and threats that may occur, then the biggest weakness is the quality of instructors and learning space into the greatest weakness.
\end{abstract}

Keywords: service quality, satisfaction , SWOT analysis.

\section{PENDAHULUAN}

\section{Latar Belakang}

Perkembangan ekonomi dan perdagangan, telah memacu perubahan struktur ekonomi dan industri yang tentunya akan mempengaruhi jumlah kebutuhan tenaga kerja sebagai sumber daya manusianya. Standar dan kualitas tenaga kerjapun perlu selalu dipertimbangkan, baik dari jenis maupun kualifikasinya yang cenderung pada kompetensi yang semakin tinggi agar mampu bersaing di pasar nasional, dan internasional. Indonesia saat ini menghadapi banyak masalah ketenagakerjaan yang sangat kompleks. Jumlah pengangguran secara akumulatif terus meningkat secara tajam, sejalan dengan meningkatnya jumlah lulusan pendidikan sekolah. Hal ini harus segera ditanggulangi agar tidak terus menambah jumlah pengangguran yang ada di Indonesia dan meningkatkan angka kemiskinan penduduknya.

Fauzi (2008) menyatakan, fenomena tingginya tingkat pengangguran di Indonesia, disebabkan oleh pertumbuhan angkatan kerja yang lebih besar daripada kesempatan kerja yang tersedia, terjadinya missmatch pendidikan dan latihan (DIKLAT) dengan kebutuhan pasar kerja serta terbatasnya informasi pasar kerja dan rendahnya efektifitas bursa kerja. Maka menurut beliau, pemerintah daerah seharusnya telah berkomitmen untuk meningkatkan kualitas sumberdaya manusia 
secara bertahap yang tertuang dalam agenda RPJMD Propinsi Bengkulu tahun 20102015 yaitu membangun sumberdaya manusia berkualitas. Membangun kualitas tersebut bisa saja dengan memprioritaskan kualitas Diklat Balai Pelatihan Kerja disetiap daerah. Fakta menyatakan bahwa pengangguran di Propinsi Bengkulu terus meningkat dalam tiga tahun terakhir (Bengkulu Dalam Angka, 2016).

Data BPS , hasil Sakernas menunjukkan tingkat persentase pengangguran terbuka di Provinsi Bengkulu pada tahun 2014 tercatat 3,5\% sedangkan pada tahun 2015 terjadi peningkatan persentase pengangguran sebesar 4,9\% peningkatan sebesar 1,4\%. Sedangkan tingkat pengangguran terbuka untuk Kota Bengkulu berdasarkan Data BPS tahun 2015-2016 mencapai 6.78\% dengan persentase penduduk yang berumur 10 tahun ke atas yang tidak tamat SD/tidak punya ijazah sebesar 19,5\%, data ini menunjukakan dominasi perempuan $20,18 \%$ bila dibanding laki-laki $18,71 \%$. Kemudian penduduk Kota Bengkulu yang menamatkan pendidikan SD, SLTP, SLTA dan Akademi/ Universitas masing-masing berjumlah 22,63\%, 19,22\%, $28,60 \%$ dan 10,10 \%. Selanjutnya data BPS Kota Bengkulu juga mencatat untuk penduduk yang berusia 15 tahun ke atas, jumlah angkatan kerjanya adalah 67,16 \% sedangkan bukan angkatan kerja berjumlah 32,84\%. Dilihat dari sektor usaha, penduduk yang bekerja paling banyak di sektor perdagangan, rumah makan dan hotel yang berjumlah $32,50 \%$. Diiringi sektor pertanian $21,65 \%$, sektor jasa kemasyarakatan 21,56 \%, sektor industri 8,80 \% dan sektor lainnya 15,48\% (bps.go.id).

Berdasarkan data-data tersebut berbagai upaya dilakukan oleh pemerintah untuk menyelesaikan permasalahan tersebut, salah satunya dengan peningkatan mutu sumber daya manusianya agar kualitas tenaga kerja di Indonesia serta Propinsi Bengkulupun semakin meningkat, dan tidak kalah dengan kualitas tenaga kerja asing. Dengan meningkatnya kualitas tenaga kerja Indonesia, maka kesempatan untuk mendapatkan pekerjaan, baik di dalam maupun di luar negeri semakin terbuka lebar, sehingga mengurangi angka pengangguran dan kemiskinan.

Elfindri dan Bachtiar (2004) mengatakan untuk mengatasi masalah ketenagakerjaan tidak terlepas dari strategi pembangunan sumberdaya manusia di negara tersebut. Maka komitmen negara yang kuat dalam membangun sumber daya manusia yang berkualitas melalui peningkatan kompetensi dan produktifitas tenaga kerja, juga ditegaskan dalam UU No. 13/ 2003 tentang ketenagakerjaan. Pemberdayaan Balai Latihan Kerja merupakan salah satu solusi untuk meningkatkan kualitas tenaga kerja, khususnya bagi masyarakat yang hanya memiliki tingkat pendidikan setara dengan SLTP dan SMA, yang biasanya memiliki keterampilan rendah dan tidak mampu melanjutkan ke jenjang pendidikan yang lebih tinggi.

Balai Latihan Kerja adalah sebuah sekolah "non profit" dibawah Dinas Ketenagakerjaan yang menampung kegiatan pelatihan untuk memberikan, memperoleh, meningkatkan serta mengembangkan keterampilan, produktivitas, disiplin, sikap kerja, dan etos kerja yang pelaksanaannya lebih mengutamakan praktek daripada teori. Balai Latihan Kerja (BLK) berfungsi untuk merumuskan kebijakan teknis di bidang pelatihan tenaga kerja, pelaksanaan pelayanan umum 
bidang pelatihan tenaga kerja dan pemberian pelayanan penunjang penyelenggaraan pemerintah daerah. BLK merupakan salah satu instrumen pengembangan sumber daya manusia yang diharapkan dapat mentransfer pengetahuan, keterampilan, dan etos kerja yang produktif sehingga nantinya mampu melahirkan sumber daya manusia yang berkualitas, kompeten dan memenuhi permintaan pasar tenaga kerja dengan berbagai kurikulum dan program yang ada di BLK. Balai Latihan kerja merupakan institusi di luar sekolah formal (pendidikan formal), yang diharapkan menjadi katub pengaman dan alternative upaya peningkatan mutu pendidikan dan keterampilan peserta didik dimana nantinya menjadi sumberdaya manusia yang terlatih (Faisal Sanapiah,1981; Joesoef Soelaiman, 2004; Purwanto, Ngalim. 1985). Kemudian, arah dan kebijakan pendidikan nasional hendaknya diselaraskan dengan kebutuhan tenaga kerja, artinya kebijakan pendidikan diarahkan pada penyelesaian masalah ketenaga kerjaan di Indonesia (Tilaar, 1998). Selanjutnya, pada kenyataannya BLK Bengkulu menghadadpi persoalan menurunnya minat orang untuk datang mengikuti pelatihan, mungkin karena apa yang ditawarkan saat ini tidak sesuai dengan kebutuhan calon tenaga kerja.

Seiring dengan perkembangan zaman dan pertumbuhan penduduk, maka kualitas dan daya tampung serta diversifikasi macam latihan di BLK perlu ditingkatkan. Pengembangan kompetensi tenaga kerja dan peningkatan produktivitas merupakan salah satu hal dalam prioritas penciptaan kesempakatan kerja nasional, dan salah satu arah pengembangan dan penguatan kompetensi adalah dengan mewujudkan BLK menjadi lembaga pelatihan berbasis kompetensi hal ini disampaikan oleh Iryanti (2009).

Berdasarkan hal-hal yang telah diuraikan, Balai Latihan Kerja (BLK) Bengkulu sedang mengalami penurunan jumlah peserta setiap tahunnya. Seperti yang diketahui bahwa kompetisi bisnis pendidikan dan pelatihan terus berkembang sesuai dengan kebutuhan dan jamannya. Melalui dimensi dan indikator kualitas pelayanan, sarana prasarana terhadap kepuasan peserta latihan itu sendiri menimbulkan rasa ingin tahu dan menarik untuk diteliti dengan pokok permasalahan, antara lain:

(1) Apakah ada pengaruh kualitas pelayanan terhadap kepuasan peserta Diklat Balai Latihan Kerja (BLK) Bengkulu?

(2) Apakah ada pengaruh sarana prasarana terhadap kepuasan peserta Diklat Balai Latihan Kerja (BLK) Bengkulu?

(3) Apakah ada pengaruh kualitas pelayanan dan sarana prasarana secara bersama-sama terhadap kepuasan peserta Diklat Balai Latihan Kerja (BLK) Bengkulu?

Berdasarkan uraian di muka, dapat dirumuskan tujuan penelitian sebagai berikut: (1) Mengetahui apakah ada pengaruh kualitas pelayanan terhadap kepuasan peserta Diklat Balai Latihan Kerja (BLK) Bengkulu. (2) Mengetahui apakah ada pengaruh sarana prasarana terhadap kepuasan peserta Diklat Balai Latihan Kerja (BLK) Bengkulu. (3). Mengetahui apakah ada pengaruh kualitas pelayanan dan sarana prasarana secara bersama-sama terhadap kepuasan peserta Diklat Balai Latihan Kerja (BLK) Bengkulu. 


\section{TINJAUAN PUSTAKA}

Customer Satisfaction, Howard dan Sheth (1969) mengungkapkan bahwa kepuasan pelanggan adalah situasi kognitif pembeli berkenaan dengan kesepadanan atau ketidak sepadanan antar hasil yang didapatkan dibandingkan dengan pengorbanan yang dilakukan. Engel, et al. (1990) menyatakan bahwa kepuasan pelanggan merupakan evaluasi purna beli dimana alternatif yang dipilih sekurangkurangnya sama atau melebihi harapan dari konsumen itu sendiri.

Kotler (2005) menyatakan kepuasan konsumen adalah perasaan senang atau kecewa seseorang yang muncul setelah membandingkan antara persepsi hasil dari suatu produk dan harapannya. Alfansi (2010) menyimpulkan bahwa perusahaan yang sukses adalah perusahaan yang melihat bisnis dari sudut pandang konsumen, memuaskan kebutuhan konsumen dengan menyediakan produk yang relevan bagi konsumen dibandingkan produk pesaing. Kepuasan konsumen menurut Wilkie (1994) yaitu merupakan respon emosional terhadap evaluasi pengalaman mengkonsumsi produk, toko atau jasa. Kepuasan merupakan tingkat perasaan konsumen yang diperoleh setelah konsumen melakukan atau menikmati sesuatu. Begitu juga dengan lemmbaga pendidikan dan latihan dapat meminjam berbagai teori serta pendapat dunia bisnis, agar peserta didik dapat puas setelah mengikuti pelatihan di BLK.

\section{Kualitas Layanan}

Kualitas pelayanan merupakan suatu bentuk penilaian konsumen terhadap tingkat pelayanan yang diterima (perceived service) dengan tingkat layanan yang diharapkan (expected service). Kualitas pelayanan mempunyai pengaruh terhadap kepuasan pelanggan (kotler, 2005). Dampak positif dari pelayanan yang baik akan meningkatkan kepuasan dan kesetiaan pelanggan serta keinginan untuk melakukan pembelian kembali (re-buying), yang tentunya akan meningkatkan pendapatan yang diterima dari produk yang telah terjual. Agar dapat bersaing, bertahan hidup, dan berkembang, maka BLK dituntut untuk mampu memenuhi kebutuhan dan keinginan pelanggan dengan memberikan pelayanan yang terbaik dan berkualitas, maka dengan begitu pelanggan akan merasa mendapat kepuasan tersendiri dan merasa dihargai sehingga mereka senang dan bersedia untuk menjadi pelanggan tetap.

\section{METODE PENELITIAN}

Dalam penelitian kualitatif, menurut (Arikunto, S. 2002; Sugiyono. 2010) maka metodologi memegang peranan penting dalam menghasilkan model atau rancangan yang hendak dicari. Berbagai metoda dapat digunakan, dalam penelitian ini digunakan adalah evaluasi diri dengan pendekatan mengevaluasi kebijakankebijakan yang telah diambil oleh Balai Latihan Kerja Propinsi Bengkulu dalam meningkatkan berbagai model interaksi pendidikan dan latihan, selama kurun 
waktu tertentu. Metode analisis kekuatan, kelemahan, peluang dan ancaman yang mungkin terjadi (SWOT). Berdasarkan hasil Analisis SWOT disusun kebijakan pendidikan dan latihan yang cocok pada BLK di wilayah Bengkulu. Untuk mendapatkan informasi dilakukan wawancara mendalam pada peserta dan alumni pendidikan dan pelatihan dan pihak manajemen pengelola BLK Bengkulu dan para pemangku kepentingan lainnya. Kemudian mengembangkan berbagai strategi, kebijakan dan penerapannya pada BLK Bengkulu yang harus dilakukan dalam memasarkan jasa BLK Bengkulu, sehingga terpenuhi kebutuhan dan tuntutan peserta didik di kemudian hari.

\section{HASIL DAN PEMBAHASAN}

Salah satu daerah yang memiliki BLK adalah Kota Bengkulu. BLK Bengkulu berdiri pada tahun 1983. Berdasarakan KEP.88/MEN/1997 BLK Bengkulu resmi dibuka untuk wilayah Provinsi Bengkulu (http://lemsar.depnakertrans.go.id). BLK Bengkulu memiliki tujuan untuk melatih keterampilan dan pelatihan kerja terhadap peserta mereka, pelatihan pun bisa sesuai dengan kejuruan yang ada. BLK Bengkulu telah memiliki 8 kejuruan, antara lain: Teknologi Mekanik, Listrik, Otomotif, juru las, Tata Niaga, Dasar-Dasar Perkantoran, Bangunan, operator mesin bubut, Pengembangan Hasil Pertanian, Aneka Kejuruan dan Produktivitas (jahit, perhotelan). Banyaknya pilihan kejuruan membuat masyarakat dapat memilih kejuruan sesuai dengan minat mereka. Fenomena yang terjadi, walaupun memiliki banyak pilihan, promosi/pemasaran yang dilakukan oleh BLK Bengkulu masih kurang maksimal. Berdasarkan observasi yang dilakukan pada BLK Bengkulu telah melakukan iklan pada koran harian Bengkulu (koran Rakyat Bengkulu), tetapi segmen BLK adalah anak muda penggangguran yang tamat Sekolah Menengah Atas. Semestinya pemasaran/promosi dilakukan di setiap sekolah-sekolah. Promosi yang dilakukan seharusnya disesuaikan dengan segmen mereka.

Kemudian, tenaga instruktur yang kurang berkompeten, merupakan kelemahan yang ada pada BLK kemudian berdampak pada masyarakat enggan untuk mengikuti pendidikan dan pelatihan di BLK. Kurang kompetennya instruktur menjadi salah satu faktor kurangnya minat masyarakat terhadap BLK Bengkulu. Hal tersebut menimbulkan ketidak percayaan terhadap kegiatan pelatihan di BLK. Berdasarkan data lembaga pencatatan data untuk sekolah kursus dan pelatihan dibawah naungan Dinasker tersebut, Balai Latihan Kerja Bengkulu memiliki 42 instruktur sebanyak 42 orang 36 laki-laki dan 6 orang perempuan. Dari 42 instruktur tersebut 7 orang memiliki pendidikan SLTA dan 18 orang memiliki pendidikan diploma, sedangkan sisanya adalah sarjana. Hampir setengah dari jumlah instruktur memiliki pendidikan dibawah sarjana. Dengan masih rendahnya pendidikan instruktur 
membuat anggapan bahwa mereka kurang kompeten dan tidak sesuai dengan pelatihan yang akan diajarkan. Keadaan ini dipandang penting untuk dibenahi. Menurut "Beni (nama disamarkan) rendahnya kompetensi instruktur ini yang membuat kami tidak percaya diri sebagai alumnus pelatihan di BLK"

Pendidikan Instruktur inilah memiliki tolok ukur harapan masyarakat terhadap BLK Bengkulu sebagai tempat kursus atau pelatihan. Pendidikan instruktur bisa saja menyebabkan kurangnya minat masyarakat terhadap BLK, yang menyebabkan turunya calon peserta tiap tahunnya. Hal tersebut dapat dilihat pada Tabel 1.1 berikut ini:

Tabel 1.1 Jumlah Peserta Pelatihan 2013-2015

\begin{tabular}{|l|c|}
\hline Tahun & Pelatihan 2013-2015 (Orang) \\
\hline $\mathbf{2 0 1 3}$ & 752 \\
\hline $\mathbf{2 0 1 4}$ & 240 \\
\hline $\mathbf{2 0 1 5}$ & 624 \\
\hline
\end{tabular}

Sumber: (http://lemsar.depnakertrans.go.id)

Penurunan peserta terjadi pada tahun 2013-2014 sebesar 512 orang namun peningkatan terjadi lagi pada tahun 2015 sebesar 624 orang, akan tetapi peningkatan tersebut masih dibawah tahun 2013. Hal tersebut bisa saja dipengaruhi oleh kualitas Sumber Daya Manusia (instruktur) yang mayoritas hanya berpendidikan SLTA dan Diploma tersebut. Selain tenaga instruktur, kualitas pelayanan dan sarana prasarana/fasilitas juga dapat mempengaruhi konsumen (Kotler 2007). Berdasarkan data (http://lemsar.depnakertrans.go.id) BLK Bengkulu hanya memiliki 55 pegawai yang melayani para peserta pelatihan untuk mendapatkan ilmu atau teori dan praktek pada pelatihan yang diadakan terasa kurang,jumlah tersebut masih sangat minim, untuk melayani para peserta. Sebanyak 55 pegawai akan sangat kewalahan untuk melayani ratusan peserta, baik dalam segi administrasi maupun ketrampilan teknis dan teoritik nantinya. Hal tersebut akan mempengaruhi harapan peserta. Penuturan "Anggita: kelemahan atau kurangnya jumlah karyawan, menyebabkan pelayanan kurang, membuat kami kurang disiplin dalam berlatih, motivasi kami menjadi menurun"

Sarana dan prasarana memberi kontribusi dalam mempengaruhi minat peserta. Purwanto, Ngalim. (1985) mengemukakan sarana prasarana adalah semua perangkat kelengkapan dasar yang secara langsung maupun tidak langsung menunjang pelaksanaan proses pendidikan di sekolah. Berikut Tabel 1.2 Daftar sarana di BLK Bengkulu 
Tabel 1.2 Daftar Sarana dan Prasarana Di BLK Bengkulu

\begin{tabular}{|l|c|c|}
\hline Ruang & $\begin{array}{c}\text { Jumlah } \\
\text { (Ruangan) }\end{array}$ & $\begin{array}{c}\text { Kapasitas } \\
\text { (Orang) }\end{array}$ \\
\hline Ruang Kelas & 1 & 80 \\
\hline Workshop & 7 & 629 \\
\hline Mushola & 1 & 49 \\
\hline R. Olahraga & 0 & 0 \\
\hline Perpustakaan & 0 & 49 \\
\hline Kantin & 1 & 0 \\
\hline
\end{tabular}

Sumber: (http://lemsar.depnakertrans.go.id)

Pada Tabel 1.2 tersebut dapat diketahui bahwa masih minimnya sarana dan Prasarana BLK Bengkulu. Pada Tabel 1.1 sebelumnya jumlah peserta pada tahun 2013 jumlah peserta didik sebanyak 752 orang yang melebihi kapasitas ruangan kelas dan workshop semestinya. Puncak kegiatan pelatihan pada BLK Bengkulu adalah tahun 2013 seiring dengan otonomi daerah, sepertinya BLK ditinggalkan oleh para pengambil kebijakan. Informasi yang dapat dihimpun dari pengelola BLK, yang dirasakan kurang adalah ruang belajar, sehingga pengaturan jadwal menjadi tidak opitimal, hal ini berakibat pada sulitnya meningkatkan ketrampilan peserta didik.

Perpustakan dan ruang olahraga masih belum ada di BLK Bengkulu. Hal ini memperkuat bahwa sarana dan prasarana di BLK Bengkulu masih sangat minim, sehingga hal ini merupakan kelemahan terbesar yang ada pada BLK Bengkulu. Menurut" Andi seorang peserta yang menjalani kegiatan mengatakan: kami jenuh latihan, terutama latihan yang durasinya berminggu-minggu, orang banyak, sarana olah raga kurang, sehingga badan tidak bugar, bagaimana mau konsentrasi pada pelatihan"

Pendapat Surtini, yang ditemui di sela-sela kesibukan pada menjahit pakaian para pelanggannya, Pelatihan di BLK Bengkulu kalau dikelola dengan baik, dapat meningkatkan ketrampilan kami, tapi kami merasa kurang maksimal dan kami merasa kurang puas terhadap BLK"

Menurut (Kotler 2005; Chou, H.J. 2009; Lin, Y. C., Lin, H. C.dan Lee, Y. C. 2007.), bahwa kepuasan pelanggan merupakan suatu perasaan senang atau kecewa 
seseorang yang muncul setelah membandingkan antara persepsi atau kesannya terhadap kinerja (hasil) suatu produk yang dihasilkan oleh perusahaan atau jasa. Kepuasan pelanggan didefinisikan sebagai evaluasi pasca konsumsi bahwa suatu alternatif yang dipilih setidaknya memenuhi atau melebihi harapan pelanggan (Engel, et al. 1990; Alkilani, K., Kwek, C.L. dan Abkhaz, A.A. (2013). Kepuasan pelanggan berkontribusi pada sejumlah aspek krusial, seperti terciptanya loyalitas pelanggan, meningkatnya reputasi perusahaan, berkurangnya elastisitas harga, berkurangnya biaya transaksi masa depan, dan meningkatnya efisiesi. Lain lagi Suroto, menyebut merasa hanya mendapat dasar-dasar ketrampilan sedikit tentang perbengkelan, selebihnya saya mencari dari tempat lain, BLK peralatannya kurang mengikuti perkembangan zaman teknologi sekarang". Perilaku semacam ini lumrah terjadi, jika manajemen BLK tidak peduli dengan konsumennya.

Pelayanan merupakan suatu bentuk penilaian konsumen terhadap tingkat pelayanan yang diterima (perceived service) dengan tingkat layanan yang diharapkan (expected service). Kualitas pelayanan mempunyai pengaruh terhadap kepuasan pelanggan (Aryani, D. dan Rosinta, F. 2010; Balqiah, T. E. 2002; Bei, L. T. Dan Chiao, Y. C. 2001). Dampak positif dari pelayanan yang baik akan meningkatkan kepuasan dan kesetiaan pelanggan serta keinginan untuk melakukan pembelian kembali (re-buying), yang tentunya akan meningkatkan pendapatan yang diterima dari produk yang telah terjual. Agar dapat bersaing, bertahan hidup, dan berkembang, maka organisasi dituntut untuk mampu memenuhi kebutuhan dan keinginan pelanggan dengan memberikan pelayanan yang terbaik dan berkualitas, maka dengan begitu pelanggan akan merasa mendapat kepuasan tersendiri dan merasa dihargai sehingga mereka senang dan bersedia untuk menjadi pelanggan (Suryanto, L., Sugiyanto, F. X. dan Sugiarti. 2002)

Bila dilihat kekuatan, kelemahan, peluang dan ancaman yang dihadapi Balai Latihan Kerja Bengkulu, maka peluang untuk berkembang masih tersedia. Hal ini dihadapkan pada masih banyaknya pemuda yang menganggur dan memerlukan penanganan yang serius. Pendapat Tono, sehari hari menjalani profesi tukang perbaiki alat-alat elektronik. "Saya alumnus pelatihan dari BLK, tapi sudah lama, sebelum era otonomi daerah. Waktu itu, para instruktur dan peralatan sebenarnya juga belum canggih seperti sekarang, tapi kami dilatih keras, bongkar pasang alat elektronik. Satu regu pagi kami urusan bongkar, satu regu siang tukang pasang dan seperti itulah metoda yang kami dapat, dan ternyata metoda itu sangat membekas"

Apa yang disampaikan saudara Tono, sejalan dengan apa yang disampaikan (Bitterman, J.M. dan Ciftciouglou, 0. 2008) pembukatian visual merupakan hal penting dalam proses membangun persepsi pelanggan. Pembuktikan metoda sangat menentukan keberhasilan kegiatan pelatihan, walaupun dengan peralatan sederhana, dengan metoda "trial and error" berdampak positif terhadap 
keterampilan peserta didik dan mampu bersaing di dunia kerja. Lalu apa yang sebenarnya mempengaruhi keberhasilan peserta didik? Peran instruktur (SDM) dan metoda sangat berpengaruh terhadap kesuksesan peserta pelatihan dan membangun kepercayaan, nama baik dan loyalitas masyarakat (peserta didik) terhadap hasil kerja suatu institusi bisnis atau instiutusi non propit seperti Balai Latihan Kerja ini ( Chaudhuri, A. Dan Holbrook, M. B. 2001; Dick, A.S. dan Basu, K. 1994 ; Khalid, A.Q. 2013)

\section{KESIMPULAN DAN SARAN}

Peningkatan kualitas pelayanan dari segi layanan dan sumber daya manusia serta sarana dan prasarana harus lebih ditingkatkan demi meningkatkan minat masyarakat, terutama para pemuda pengangguran terhadap BLK Bengkulu, yang akan beurujung pada kepuasan peserta. Angka pengangguran yang melonjak, bila tidak dikelola akan menjadi mala petaka bagi Propinsi Bengkulu. Salah satu katub pengaman adalah meningkatkan kualitas BLK itu sendiri. tenaga kerja yang terdidik dan terlatih akan berkontribusi terhadap pengurangan pengangguran terbuka yang semakin besar jumlahnya. Sehingga kepuasan dari peserta terlatih merupakan hal mutlak yang harus dipenuhi oleh para pengelola BLK.

Dari berbagai model dan metoda pelatihan yang ada, maka Model pelatihan trial and error pada peserta didik menentukan kesuksesan peserta didik setelah memasuki dunia kerja. Peran instruktur (SDM) dan metoda sangat berpengaruh terhadap kesuksesan peserta pelatihan di kelak kemudian hari.

Berdasarkan kekuatan, kelemahan, peluang dan ancaman yang mungkin terjadi, maka kelemahan terbesar adalah kualitas instruktur dan ruang belajar menjadi kelemahan tersbesar. Oleh karena itu, di masa depan peningkatan mutu sumberdaya manusia,terutama instruktur dan ruang belajar sangat diperlukan pengelolaan serta pengadaannya dalam waktu dekat.

\section{DAFTAR PUSTAKA}

Alfansi, L. 2010. Financial Service Marketing: Membidik Konsumen Perbankan Indonesia. Jakarta: Salemba Empat.

Alfansi, L. 2012. Pemasaran Jasa Finansial: Financial Service Marketing.Edisi ke-2. ISBN. 978-979-061-254-9.Jakarta: Salemba Empat.

Alkilani, K., Kwek, C.L. dan Abkhaz, A.A. (2013).The Impact of Experiential Marketing and Customer Satisfaction on Customer Commitment in the World of Social Networks. Asian Social Science. Vol. 9, No. 1. ISSN 1911-2017 E-ISSN 1911-2025. 
Andreassen, T.W. dan Lindestad, B. 1998. Customer Loyalty and Complex Service: The Impact of Corporate Image on Quality, Customer Satisfaction and Loyalty for Customer With Variyng Degree s of Service Expertise. International Journal of Service Industry Management. Vol.9.

Arikunto, S. 2002. Prosedur Penelitian Suatu Pendekatan Praktis. Yogyakarta: Bina Aksara.

Aryani, D. dan Rosinta, F. 2010. Pengaruh Kualitas Layanan Terhadap Kepuasan pelanggan dalam Membentuk Loyalitas Pelanggan. Jurnal Ilmu Administrasi dan Organisasi. Vol. 2, No.1

Balqiah, T. E. 2002. Pengukuran Afeksi dan Kepuasan Pelanggan: Kasus Penumpang PT Pelita Air Service. Jurnal Manajemen Indonesia. Vol.1, No.1

Bei, L. T. Dan Chiao, Y. C. 2001, an Integrated Model For The effect of perceived product, perceived service quality dan perceived price fairness on consumer satisfaction and loyalty. Journal of Consumer Ssatisfaction, Dissatisfaction anf Complaining Behaviour. Vol.1 ,No. 2

Bitterman, J.M. dan Ciftciouglou, 0. 2008.Visual perception model for architectural design. Faculty of Architecture, Delft University of Technology. Delft Netherland.

Chaudhuri, A. Dan Holbrook, M. B. 2001. The chain of effect From Brand Trust and Brand Affect to Brand Performance: The Role of Brand Loyalty. Journal of Marketing. Vol. 2, No.1.

Chou, H.J. 2009. Social Behaviour and Personality. The Effect Of Experiential And Relationship Marketing On Customer Value: A Case Study Of International Amarican Dining Chains In Taiwan.International Journal of Service Industry Management.Vol. 6, No. 3..

Dick, A.S. dan Basu, K. 1994. Customer Loyalty: Toward an Integred Conceptual Framework. Journal of Academy of Marketing Science. Vol. 22.

Elfindri dan Bachtiar, Nasri, 2004, Ekonomi Ketenagakerjaan, Andalas University. Press, Padang.

Engel, J.F., Blackwell, R.D. dan Miniard, P.W. 1990. Consumer Behaviour. Edisi 6. Jakarta: Binarupa Aksara.

Faisal Sanapiah, 1981, Pendidikan Luar Sekolah . Surabaya: CV. Usaha Nasional.

Fauzi, akhmad. 2008. Antesden Stres Terhadap Kinerja Dan Kepuasan Kerja Pada. Wartawan Di Jawa Timur, Jurnal aplikasi manajemen,volume 6 nomor 1.

Fida, F. 2013. Pengaruh Bauran Pemasaran terhadap Kepuasan Konsumen Air Mineral Asa di Samarinda. ejournal.adbisnis.fisip-unmul.ac.id. Vol. 1, No. 4

Griffin, J. 2002. Customer Loyalty How to Earn it, How to Keep it. Kentucky: Mc GrawHill.

Haeckel. 2003. How to Lead The Customer Experience. Prentice Hall.

Hafeez, S. dan Bakhtiar, M. 2012. The Impact of Service Quality, Customer Satisfaction and loyalty Programs on Customers Loyalty, Evidence form Banking Sector of Pakistan. International Journal of Business and Social Science.Vol. 3, No. 16.

Howard, J.A. dan Sheth, J.N. 1969.Theory of Buyer Behaviour, Wiley New York, NY. Journal Marketing.Vol. 60. 
Joesoef Soelaiman, 2004, Konsep Dasar Pendidikan Luar Sekolah. Jakarta: PT. Bumi Aksara.

Khalid, A.Q. 2013. The Evolution of Experiental Marketing: Effect of Brand Experience among The Millennial Generation.International Journal of Academic Research and Social Sciences. Vol. 3, No. 7.

Kotler, P. 2005. Manajemen Pemasaran, Jilid 1 dan 2 Jakarta: Indeks Kelompok Gramedia.

Lin, Y. C., Lin, H. C.dan Lee, Y. C. 2007. The Study of the Relationship among Experiential Marketing, Customer Satisfaction and Customer Loyalty. Journal of Customer Satisfaction. Vol. 3, No. 2.

Matzler, et.al. 2005. The Relationship Between Personality and Customer Satisfaction. Self-Satisfaction Journal Innovative Marketing. Vol. 1, No.2.

Pemerintah Republik Indonesia, UU No. 13/ 2003 tentang ketenagakerjaan. Pemberdayaan Balai Latihan Kerja.

Purwanto, Ngalim. 1985. Ilmu Pendidikan. Bandung, CV. Remaja Karya.

Sugiyono. 2010. Metode Penelitian Bisnis. Bandung: Alfabeta.

Suryanto, L., Sugiyanto, F. X. dan Sugiarti. 2002. Analisis Faktor-faktor Pembentuk Kualitas Layanan untuk Menciptakan Kepuasan dan Loyalitas Pelanggan. Jurnal Bisnis Strategi. Vol. 9, No. 1

Tilaar. 1998.Paradigma Baru Pendidikan Nasional . Jakarta: Rineka Cipta.

Wilkie, W. L. 1994. Find Great Deals for Consumer Behavior, Third Edition. England: John Wiley \& Sons Inc Publisher

(http://lemsar.depnakertrans.go.id 